\title{
The Effects of Video Information on Delirium, Anxiety, and Nursing Satisfaction of Heart Surgery Patients
}

\author{
Won Jin Lee ${ }^{1}$, Mi Joon Lee², Sang Gwon $\mathrm{Kang}^{3}$ and Yun Yi Bang ${ }^{4}$ \\ ${ }^{1}$ Nurse, MSN, Kangbuk Samsung Hospital, Republic of Korea \\ ${ }^{2}$ Manager, PhD, Health team, Kangbuk Samsung Hospital, Republic of Korea \\ ${ }^{3}$ CFO, PhD, Kangbuk Samsung Hospital, Republic of Korea \\ ${ }^{4}$ Nurse, MSN, Kangbuk Samsung Hospital, Republic of Korea \\ 03181, 29 Saemunan-ro, Jongno-gu, Seoul, Korea \\ 1stella2831@naver.com, ${ }^{2}$ mijoon63@naver.com, ${ }^{3}$ sanggwon.kang@samsung.com, \\ ${ }^{4}$ beebee732@naver.com \\ *Corresponding Author: Mi Joon Lee
}

\begin{abstract}
Open heart surgery patients exhibit greater prevalence of delirium and moderate or higher level of anxiety. These symptoms may hinder postoperative recovery and health, and may even lead to complications. The objective of this study was to determine the effects of preoperative video information on delirium, anxiety, and nursing satisfaction of open heart surgery patients. This quasiexperimental study utilized a nonequivalent control group with a non-synchronized design, and was conducted from March 15, 2012 to December 1, 2014. The subjects consisted of 50 patients, of whom 25 comprised the experimental group and 25 the control group. On the day prior to surgery, the experimental group was provided with informative videos while the control group was provided with information through traditional medium. Delirium was diagnosed through CAM-ICU, while anxiety levels and Nursing Satisfaction were determined through STAI and questionnaire, respectively. Data was analyzed through SPSS WIN 21.0. The results showed no statistically significant difference $(p=.260)$ in delirium incidences, but improvements were observed in anxiety levels $(p=.028)$ and nursing satisfaction $(p=.004)$. Thus, this study recommends the use of video information as part of nursing intervention for open heart surgery patients so as to reduce their anxiety levels and improve nursing satisfaction.
\end{abstract}

Keywords: Open heart surgery, Video information, Delirium, Anxiety, Nursing satisfaction

\section{Introduction}

Delirium is an acute neuropsychiatric syndrome encompassing an array of symptoms such as disruptions in cognitive functions, psychopathy, and interruptions in sleep-wake cycle, perceptual disorder, disorders of thought, language dysfunction, and mood swings [1]. The prevalence of delirium is higher for elderly patients, postoperative patients, and burn patients [2]. Patients who experience delirium are reported to have increased mortality and longer hospitalization as compared to non-delirious patients [2]. Delirium symptoms often occur within two or three days of the patients' entry into the intensive care unit (ICU). Most of the symptoms last for several weeks and disappear within a month, and the patients often do not remember their delirious conditions [3]. Mild delirium results in only a slight delay in thought process, but severe delirium results in considerable 
disturbances to the thought process. Such patients are unable to cooperate with the medical staff, which hinders effective treatment [3].

Postoperative incidences of delirium are reported to be $7 \sim 14 \%$ for general surgery, $5.7 \%$ for urology surgery, and $13.5 \sim 21 \%$ for heart surgery [4]. In particular, postoperative delirium is more prevalent among open heart surgery patients. Postoperative delirium symptoms are easy to overlook if the medical staff lacks knowledge and experience [5]. Furthermore, delirium is a common yet severe problem among patients at the ICU [5]. Most of the local researches on postoperative delirium were conducted by Chung and Lee $[6,7]$. However, there is a considerable lack of research regarding nursing interventions aimed at preventing delirium incidences among open heart surgery patients.

Anxiety is a reaction to stress and a subjective emotional response that results in loss of internal control over concerns, stress, worries, and imminent danger [8]. Preoperative patients display anxiety over their surgical outcomes; this anxiety stimulates their autonomic nervous systems and results in increased blood pressure and arrhythmia [9]. These symptoms can have a negative impact on the surgical outcome and recovery [9]. Anxiety can hinder postoperative recovery and cause complications, which is why it should be treated in the early phases [10].

In the case of open heart surgery patients, $60 \%$ show moderate or higher level of anxiety [11]. Open heart surgery is a major surgery, and as such, patients experience greater uncertainty regarding their postoperative recovery as compared to other types of surgery [12]. Many studies have been conducted on easing preoperative anxiety and discomfort. Yang's study on the effects of musical therapy on obstetric surgery showed positive alleviation of anxiety symptoms [9], while Shin studied the effects of prior information on anxiety for open heart surgery patients [13].

Prevention is crucial for delirium and anxiety patients. Recent nursing interventions include provision of information through various media (e.g., booklets, videos, slides, and patient status boards) so as to ease delirium, anxiety, pain, and stress among postoperative patients [14]. There is a higher demand among patients for nursing intervention that includes explanations on operating room environments and ICU environments [16]. When nurses fulfill such patient demands, they are able to reduce incidences of delirium and anxiety while improving nursing satisfaction [15]. Provision of information offers physical and psychological stability to patients and their families, and induces behavioral changes that can further diminish anxiety and depression over hospital stays [16]. New suggestions have been put forward so as to repeatedly provide information that can be easily accepted by patients; these include providing full explanation regarding all measures that need to be taken, encouraging patient participation, and offering orientation [17]. Current literature on nursing intervention through information provision includes studies on providing nursing information and its effects on anxiety and environmental stress of open heart surgery patients [13]. However, there is still a conspicuous lack of research on the effects of nursing intervention in the form of preoperative video information on delirium, anxiety, and nursing satisfaction among open heart surgery patients.

In this study, open heart surgery patients were provided with informative videos that explained preoperative procedures, operating room environment, and ICU environment on the day prior to their surgery. This study determined the effects of such information on delirium, anxiety, and nursing satisfaction so as to establish a baseline data for effective nursing intervention. 


\section{Methods}

\subsection{Research Design}

This quasi-experimental study utilized a nonequivalent control group with nonsynchronized design. The main objective was to explore the effects of preoperative video information on delirium, anxiety, and nursing satisfaction among open heart surgery patients.

\subsection{Subjects}

This study was conducted among patients hospitalized at the cardiothoracic department of K Hospital in Seoul. The number of subjects selected was consistent with existing research [15]; the $G^{*}$ Power program version 3.1.9.2 was used with a significance level set at 0.05 , effective size at 0.8 , and test power at 0.7 . The total number of samples was 50 , of which 25 were assigned to the experimental group while 25 subjects were included in the control group.

The selection of test subjects adhered to the following criteria.

\subsubsection{Criteria for Test Subjects}

- Patients on respirators and confined at the ICU after open heart surgery

- Patients who can read and write, and understand and reply to the survey questionnaire

- Patients who gave their consent to participate in the study

- Patients 20 years of age or older

\subsubsection{Criteria for Exclusion}

- Patients with preexisting delirium symptoms or cognitive dysfunctions prior to surgery

- Patients who received surgery after entering the ICU

\subsection{Research Tools and Reliability}

2.3.1. Delirium: The Confusion Assessment Method of the ICU (CAM-ICU), which was developed by Ely [18], is an assessment tool that enables the medical staff to effectively diagnose delirium symptoms. This study used the CAM-ICU as adapted by Chang and Choi [19]. The questionnaire consists of four questions, and if the patient gives a positive response for more than two questions, it indicates incidence of delirium. The reliability was Cronbach's=.973.

2.3.2. Anxiety: Anxiety symptoms were measured by employing a tool adapted by Kim and Shin [21], which was based on the State-Trait Anxiety Inventory (STAI) developed by Speilberger [20]. The questionnaire consists of 20 questions and is scored on a 4-point scale. Ten of the questions include negative sentiments, and a higher score indicates higher anxiety levels. The reliability of this study was Cronbach's=.922.

2.3.3. Nursing Satisfaction: The nursing satisfaction was measured by using the 19-item questionnaire developed by Bisser [22]. Higher scores indicate higher nursing satisfaction. The reliability of this study was Cronbach's=.932. 


\subsection{Data Collection}

For ethical considerations, this study was conducted after receiving approval from the Biomedical Ethics Committee of the institution affiliated with this study (IRB Approval number: 2012-01-117). Data was compiled from all subjects who gave their consent to participate in the study; the study was conducted from March 15, 2012 to December 1, 2014. A preliminary inspection was conducted on the day before the patient received open heart surgery, and included general characteristics, disease characteristics, and anxiety levels of the patient. On the day before the heart surgery, the experimental group was provided with informative videos on preoperative procedures in the general ward, operating room environment, and ICU environment. On the other hand, the control group was provided with preexisting information measures. For the assessment of anxiety and delirium after intervention, patients were surveyed prior to moving out of the ICU into the general ward. The satisfaction survey was conducted at the general ward on the day before discharge.

\subsection{Analysis}

The collected data were analyzed through SPSS WIN 21.0. The general characteristics and disease characteristics were analyzed with real numbers, percentages, mean, and standard deviation. The $x^{2}$-tests, Fisher's exact test, and $t$ tests were used to analyze the homogeneity of the two groups. The verification of differences between the two groups for delirium and nursing satisfaction was determined by an independent $t$-test. The difference in anxiety levels was analyzed using the paired $t$-tests.

\section{Results}

\subsection{Homogeneity Test on the General and Disease Characteristics of Patients in the Experimental and Control Groups}

The general characteristics and disease-related characteristics showed no statistically significant difference for the experimental group and control group thus, confirming that both groups were homogenous (Table 1). There were more female subjects in both the experimental and control groups. The average age was 58.8 for the experimental group and 61.1 for the control group. The education levels were evenly distributed for both groups. 6 patients in the experimental group (24\%) and 5 patients in the control group (20\%) responded that they had previous experience of viewing informative videos prior to surgery, indicating that roughly a quarter of the subjects had prior video provision experiences. 9 patients in the experimental group (36\%) and 4 patients in the control group (16\%) had prior experience of being hospitalized in the ICU. The average operation time was $329 \pm 145$ minutes for the experimental group and $319 \pm 98$ minutes for the control group. 
Table 1. Homogeneity Test on the General and Disease Characteristics of Patients in the Experimental Control Groups ( $\mathrm{N}=50)$

\begin{tabular}{|c|c|c|c|c|c|}
\hline \multirow[t]{2}{*}{ Characteristic } & \multirow[t]{2}{*}{ Categories } & $\begin{array}{l}\text { Exp. } \\
\text { group } \\
(\mathrm{n}=25)\end{array}$ & $\begin{array}{l}\text { Cont. group } \\
\quad(\mathrm{n}=25)\end{array}$ & \multirow[t]{2}{*}{$\mathrm{t}$} & \multirow[t]{2}{*}{$p$} \\
\hline & & \multicolumn{2}{|c|}{$\mathrm{N}(\%)$ or Mean $\pm \mathrm{SD}$} & & \\
\hline \multirow{2}{*}{ Gender } & Female & $15(54)$ & $13(46)$ & \multirow{2}{*}{0.32} & \multirow{2}{*}{.569} \\
\hline & Male & $10(46)$ & $12(54)$ & & \\
\hline Age & & $58.8 \pm 16.2$ & $61.1 \pm 12.9$ & 0.57 & .571 \\
\hline \multirow{5}{*}{$\begin{array}{l}\text { Education } \\
\text { levels* }\end{array}$} & Illiteracy & $1(4)$ & $3(12)$ & \multirow{5}{*}{3.69} & \multirow{5}{*}{.770} \\
\hline & $\begin{array}{l}\text { Less than elementary } \\
\text { school }\end{array}$ & $7(28)$ & $6(24)$ & & \\
\hline & Less than middle school & $6(24)$ & $4(16)$ & & \\
\hline & Less than high school & $5(20)$ & $7(28)$ & & \\
\hline & More than university & $6(24)$ & $5(20)$ & & \\
\hline \multirow{4}{*}{$\begin{array}{l}\text { Experienced } \\
\text { of } \\
\text { information } \\
\text { Experienced } \\
\text { of } \\
\text { ICU } \\
\text { admission }\end{array}$} & Yes & $6(24)$ & $5(20)$ & \multirow{2}{*}{0.11} & \multirow{2}{*}{.733} \\
\hline & No & $19(76)$ & $20(80)$ & & \\
\hline & Yes & $9(36)$ & $4(16)$ & \multirow[b]{2}{*}{7.21} & \multirow[b]{2}{*}{.071} \\
\hline & No & $16(64)$ & $21(84)$ & & \\
\hline $\begin{array}{l}\text { Operation } \\
\text { time(min) }\end{array}$ & & $329 \pm 145$ & $319 \pm 98$ & -0.27 & .782 \\
\hline
\end{tabular}

*Fisher's exact test, Exp. $=$ Experimental, Cont. $=$ Control

3.2. Homogeneity Test before the Experiment on the Anxiety of the Experimental and Control Groups

The anxiety level scores prior to the provision of video information was $37.50 \pm 7.58$ for the experimental group and $41.65 \pm 14.43$ for the control group. This indicated that there was no statistically significant difference $(\mathrm{t}=1.18, p=.244)$ between the two groups, thus confirming the homogeneity of the subjects (Table 2).

Table 2. Homogeneity Test Before the Experiment on the Anxiety of the Experimental and Control Groups ( $\mathrm{N}=50)$

\begin{tabular}{|c|c|c|c|c|}
\hline \multirow[t]{2}{*}{ Categories } & $\begin{array}{l}\text { Exp. group } \\
(n=25)\end{array}$ & $\begin{array}{l}\text { Cont. group } \\
\quad(n=25)\end{array}$ & \multirow[t]{2}{*}{$\mathrm{t}$} & \multirow{2}{*}{$p$} \\
\hline & \multicolumn{2}{|c|}{ Mean \pm SD } & & \\
\hline Anxiety & $37.50 \pm 7.58$ & $41.65 \pm 14.43$ & 1.18 & .244 \\
\hline
\end{tabular}




\subsection{Comparison of Delirium Incidence between the Experimental and Control Groups}

There was no statistically significant difference in the incidence of delirium between the experimental group and the control group $(\mathrm{t}=1.50, p=.260)$. Although the results showed no statistical significance, the incidence of delirium was observed in 5 patients $(20 \%)$ in the control group, while the same was observed for only 3 patients $(12 \%)$ in the experimental group (Table 3 ).

Table 3. Comparison of Delirium Incidence between the Experimental and Control Groups ( $\mathrm{N}=50)$

\begin{tabular}{|c|c|c|c|c|c|}
\hline \multirow{2}{*}{\multicolumn{2}{|c|}{ Categories }} & $\begin{array}{l}\text { Exp. group } \\
(n=25)\end{array}$ & $\begin{array}{l}\text { Cont. group } \\
\qquad(\mathrm{n}=25)\end{array}$ & \multirow[t]{2}{*}{$\mathrm{t}$} & \multirow{2}{*}{$p$} \\
\hline & & \multicolumn{2}{|c|}{$\mathrm{N}(\%)$} & & \\
\hline \multirow{2}{*}{ Delirium } & Yes & $3(12)$ & $5(20)$ & \multirow{2}{*}{1.50} & \multirow{2}{*}{.260} \\
\hline & No & $22(88)$ & $20(80)$ & & \\
\hline
\end{tabular}

Exp. =Experimental, Cont. $=$ Control

\subsection{Comparison of the Anxiety between the Experimental and Control Groups}

The anxiety levels for the experimental group and the control group showed a statistically significant decrease for the experimental group, from an average score of $37.5 \pm 7.58$ prior to the experiment to a score of $25.8 \pm 10.39$ after the experiment $(\mathrm{t}=2.84, p=.001)$. Comparing the two groups after the experiment, there was a statistically significant decrease in the level of anxiety $(\mathrm{t}=2.27, p=.028)$ (Table 4).

Table 4. Comparison of the Anxiety between the Experimental and Control Groups( $\mathrm{N}=42)$

\begin{tabular}{|c|c|c|c|c|c|c|c|}
\hline \multirow[t]{2}{*}{ Group } & Pre test & Post test & Diff & \multirow{2}{*}{$\begin{array}{c}\text { Paired- } \\
t\end{array}$} & \multirow[t]{2}{*}{$p$} & \multirow[t]{2}{*}{$\mathrm{t}$} & \multirow[t]{2}{*}{$p$} \\
\hline & & Mean \pm SD & & & & & \\
\hline $\begin{array}{l}\text { Exp. group } \\
\quad(n=22)\end{array}$ & $37.5 \pm 7.58$ & $\begin{array}{c}25.8 \pm 10.3 \\
9\end{array}$ & $\begin{array}{c}11.7 \pm 11.7 \\
6\end{array}$ & 2.84 & .001 & \multirow[b]{2}{*}{2.27} & \multirow[b]{2}{*}{.028} \\
\hline $\begin{array}{l}\text { Cont. } \\
\text { group } \\
(\mathrm{n}=20)\end{array}$ & $\begin{array}{c}41.6 \pm 14.4 \\
3\end{array}$ & $\begin{array}{c}34.5 \pm 14.2 \\
8\end{array}$ & $7.1 \pm 17.88$ & 2.93 & .010 & & \\
\hline
\end{tabular}

Exp. =Experimental, Cont. $=$ Control

\subsection{Comparison of the Nursing Satisfaction between the Experimental and Control Groups}

The nursing satisfaction of the experimental group and the control group showed a statistically significant difference. The experimental group scored $26.36 \pm 73.53$ while the control group scored 22.80 $\pm 4.80(\mathrm{t}=-2.98, p=.004)$ (Table 5). 
Table 5. Comparison of the Nursing Satisfaction between the Experimental and Control Groups ( $=50)$

\begin{tabular}{|c|c|c|c|c|}
\hline \multirow[t]{2}{*}{ Categories } & $\begin{array}{l}\text { Exp. group } \\
\quad(n=25)\end{array}$ & $\begin{array}{l}\text { Cont. group } \\
\qquad(\mathrm{n}=25)\end{array}$ & \multirow[t]{2}{*}{$\mathrm{X}^{2}$ or $\mathrm{t}$} & \multirow[t]{2}{*}{$p$} \\
\hline & \multicolumn{2}{|c|}{ Mean \pm SD } & & \\
\hline Nursing satisfaction & $26.36 \pm 73.53$ & $22.80 \pm 4.80$ & -2.98 & .004 \\
\hline
\end{tabular}

Exp. =Experimental, Cont. $=$ Control

\section{Discussion}

This study provided informative video to open heart surgery patients on the day prior to their surgery and subsequent ICU hospitalization so as to offer detailed information on ward management prior to surgery, surgical procedures, operating room environment, ICU environment and management. The objective was to determine the effects of providing prior informative video on delirium, anxiety, and nursing satisfaction of open heart surgery patients. These patients were confined at the ICU for a short period of time, during which they were exposed to unfamiliar environments, medical equipment, limited movements, and anxiety from other patients confined at the ICU. In this study, patients were given detailed information on their nursing environments on the day before the surgery. Details included preoperative and postoperative procedures and the use of respirators, restraints, central venous catheterization, arterial tubes, thoracic ducts, and foley catheters.

The patients were diagnosed for delirium tendencies through the use of CAMICU. Delirium was observed in three patients (12\%) for the experimental group while the control group had five incidences $(20 \%)$ - this was statistically insignificant $(\mathrm{t}=1.50, p=.260)$, but a decrease nonetheless. This result was similar to the studies of Jang and Choi [19], which also showed that provision of informative videos resulted in decrease of delirium incidences in the experimental group, although the difference with the control group had no statistical significance. However, the decrease in delirium incidences points to the need for further research with an expanded number of subjects.

When nursing intervention and informative videos were provided to the patients, their anxiety levels showed a marked decrease; for the experimental group, anxiety scores significantly decreased from $37.5 \pm 7.58$ to $25.8 \pm 10.39$. On the other hand, a slight decrease was observed in the control group, from $41.6 \pm 14.43$ to $34.5 \pm 14.28$. Thus, the results indicated a statistically significant decrease in anxiety levels when informative videos were provided to the patients as part of a nursing intervention $(\mathrm{t}=2.27, p=.028)$. Patients who awaited surgery experienced greater anxiety regarding the surgical environment, unfamiliar surgical equipment, ICU environment, and other medical equipment that may be attached to the patients prior to being moved to the operating room.

Prior research conducted by Yun and Lee [14] attempted to ease anxiety through real time nursing intervention. Their research examined patients confined at the ICU and revealed that the experimental group provided with leaflets demonstrated lower anxiety levels as compared to the control group. These results were similar to the results obtained in this study. Prior research on chronic otitis media patients facing surgery also revealed lower anxiety levels after nursing intervention, which included provision of booklets prior to surgery [23]. In short, provision of information prior to surgery is reported to have an effect on lowering the anxiety level of patients. As 
such, further research should be conducted on the effectiveness of proper information provision to patients based on the conditions of ICU patients.

In the experimental group, which was provided with informative videos, the nursing satisfaction score was $26.36 \pm 73.53$. On the other hand, the control group obtained a score of $22.80 \pm 4.80$; thus, there was statistically significant difference between the two groups $(\mathrm{t}=-2.98, p=.004)$. This result was consistent with prior research conducted by Jung [24] which showed that video information prior to treatment resulted in higher satisfaction among thyroid cancer patients who underwent radioactive iodine treatment. This was also consistent with the research conducted by Lim [25] which showed higher satisfaction among patients facing vocal cord surgeries. Accordingly, information provision and education should be considered important responsibilities of nurses, and further measures should be developed in educating patients in order to improve their satisfaction levels. The effectiveness of patient education may vary based on the information preference or anxiety levels of the patients. As such, variances among patients must be surveyed in order to develop appropriate video contents, timing of education, and number of exposure to informative materials.

\section{Conclusion}

The results of this study revealed that video information decreased anxiety levels and improved nursing satisfaction among patients who face open heart surgery and subsequent ICU hospitalization. Therefore, it is deemed that such measures can serve as effective nursing intervention methods for clinical application so as to reduce anxiety levels and improve nursing satisfaction. For a general application of the results, however, further research must be conducted on a wider variety of operative patients to confirm the effects of video information provision on delirium, anxiety, and nursing satisfaction. In order to develop a proper nursing intervention, further research is also required to determine the video content, timing of education, and number of exposure to informative materials. Finally, video information is shown to be effective in reducing anxiety levels and improving nursing satisfaction among open heart surgery patients. Thus, nurses should receive systematic education on the use of video information as part of nursing intervention.

\section{References}

[1] T. M. Brown and M. F. Boyle, "Delirium", British Medical Journal, vol. 325, no. 7365, (2002), pp. 644.

[2] S. White, "The neuropathogenesis, of delirium", Reviews in Clinical Gerontology, vol. 12, no. 1, (2002), pp. 62-67.

[3] A. Granberg, I. B. Engberg and D. Lundberg, "Intensive care syndrome: a literature review", Intensive and Critical Care Nursing, vol. 12, no. 3, (1996), pp. 173-182.

[4] V. D. S. C. Vila, L. A. Rossi and M. C. S. Costa, "Heart disease experience of adults undergoing coronary artery bypass grafting surgery", Revista de Saúde Pública, vol. 42, no. 4, (2008), pp. 750-756.

[5] E. W. Ely, A. Shintani, B. Truman, T. Speroff, S. M. Gordon, F. E. Harrell. Jr and R. S. Dittus, "Delirium as a predictor of mortality in mechanically ventilated patients in the intensive care unit", Jama, vol. 291, no. 14, (2004), pp. 1753-1762.

[6] M. H. Chung, S. O. Yun, S. O. Chu, S. Y. Oh and M. Y. Kim, "Predictors of delirium in patients after orthopedic surgery", Journal of Korean Clinical Nursing Research, vol. 17, no. 3, (2011), pp. 443-454.

[7] Y. W. Lee, H. B. Im, E. Jeong and H. S. Ma, "Influencing Factors of the Incidence of Delirium in Elderly Patients with Arthroplasty", Korean N Adult Nurs, vol. 24, no. 4, (2012), pp. 348-357.

[8] S. Videbeck, "Psychiatric-mental health nursing", Lippincott Williams \& Wilkins, (2013).

[9] J. L. Yang, M. Y. Noh and K. H. Yang, "Effect of favorite music therapy on anxiety and vital sign in patients undergoing gynecologic surgery using the general anesthesia", Journal of the Korea AcademiaIndustrial Cooperation Society, vol. 16, no. 2, (2015), pp. 1189-1199.

[10] A. T. Watson and A. Visram, "Children's preoperative anxiety and postoperative behavior", Pediatric Anesthesia, vol. 13, no. 3, (2003), pp. 188-204.

[11] C. K. Koh, "Patients' anxiety in intensive care unit and its related factors", Taehan Kanho Hakhoe chi, vol. 37, no. 4, (2007), pp. 586-593. 
[12] V. D. S. C. Vila, L. A. Rossi and M. C. S. Costa, "Heart disease experience of adults undergoing coronary artery bypass grafting surgery", Revista de Saúde Pública, vol. 42, no. 4, (2008), pp. 750-756.

[13] K. M. Shin and H. R. Choi, "Effects of Prior Information About Intensive Care Unit Environment on Anxiety and Environmental Stress in Patients Undergoing Open Heart Surgery", Journal of Korean Academic Society of Nursing Education, vol. 21, no. 1, (2015), pp. 109-116.

[14] J. Y. Yun and K. E. Lee, "Effect of Nursing Information on ICU Patient's Environmental Stress, Anxiety and Comfort", Journal of Korean Biological Nursing Science, vol. 13, no. 2, (2011), pp. 109-116.

[15] G. Biancofiore, M. L. Bindi, A. M. Romanelli, L. Urbani, F. Mosca and F. Filipponi, "Stress- inducing factors in ICUs: What liver transplant recipients experience and what caregivers perceive", Liver transplantation, vol. 11, no. 8, (2005), pp. 967-972.

[16] M. J. Koo, M. H. Kim and S. K. Hwang, "The effects of the nursing education program on the knowledge, anxiety, and coping behavior of mothers with young child undergoing cardiac surgery", Korean Journal of Adult Nursing, vol. 21, no. 6, (2009), pp. 628-638.

[17] S. Saxena and D. Lawley, "Delirium in the elderly: a clinical review", Postgraduate medical journal, vol. 85, no. 1006, (2009), pp. 405-413.

[18] E. W. Ely, S. K. Inouye, G. R. Bernard, S. Gordon, J. Francis, L. May and R. Dittus. R, "Delirium in mechanically ventilated patients: validity and reliability of the confusion assessment method for the intensive care unit (CAM-ICU)", Jama, vol. 286, no. 21, (2001), pp. 2703-2710.

[19] I. S. Jang and M. H. Choi, "The effect of the environmental nursing intervention on ICU delirium, environmental stress and sleep in patients underwent cardiac surgical procedures", Journal Korean Clin Nurs Res, vol. 14, no. 2, (2008), pp. 127-138.

[20] C. D. Spielberger, "Conceptual and methodological issues in anxiety research", Anxiety: Current trends in theory and research, vol. 2, (1972), pp. 481-493.

[21] J. T. Kim and D. K. Shin, "A study based on the standardization of the STAI for Korea", Journal of New Med, vol. 21, no. 11, (1978), pp. 69-75.

[22] N. L. Risser, "Development of an instrument to measure patient satisfaction with nurses and nursing care in primary care settings", Nursing Research, vol. 24, no. 1, (1975), pp. 45-51.

[23] E. Y. Kim, "The Effects of preoperative nursing information on post-operative uncertainty and anxiety of patients with chronic otitis media", Unpublished master's thesis, Eulji University, Daejeon, (2010).

[24] M. Y. Jung, I. K. Hong, H. Y. Noh, H. S. Park, J. M. Son, J. H. Kim and S. Y. Kim. S. Y, "Effects of Video-Based Information Provision on Anxiety and Education Satisfaction of Thyroid Cancer Patients Undergoing Radioiodine Treatment”, Journal of Korean Clinical Nursing Research, vol. 21, no. 1, (2015), pp. 11-20.

[25] Y. H. Lim, I. S. Suh and S. H. Chung, "Effects of surgery information service on one-day surgery patients' anxiety and satisfaction with nursing care", Korean Journal of Adult Nursing, vol. 22, no. 1, (2010), pp. 1-10.

[26] W. J. Lee, M. J. Lee, S. G. Kang and Y. Y. Bang, "The Effects of Open Heart Surgery Patients Proving for Video Information", Advanced Science and Technology Letters, vol.128, (Healthcare and Nursing 2016), (2016), pp. 160-164.

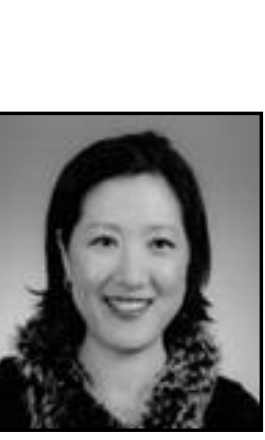

\section{Authors}

Mi Joon Lee, she is a RN, Ph.D, is a lecturer of the School of Nursing in Hanyang University located in Seoul, Korea. She built her career as a head nurse of SungAe General Hospital in 1988 1998, and Mizmedi General Hospital in 2001 2002, after receiving her B.A. (1988) at Hanyang University. She also received her M.S. (2005) in Health Information at YonSei University, and her Ph.D. in Nursing (2015) from Hanyang University. Now she is working in the healthcare strategy and plan of KangBuk Samsung Hospital as a team manager. She participated in several government projects such as 'Smartcare uHealth' in 2010 2012, and 'Development of WISE HF Sanhujori Guideline' in 2013 sponsored by Korean Government. She focuses her studies on health policy, health care system and health service. 

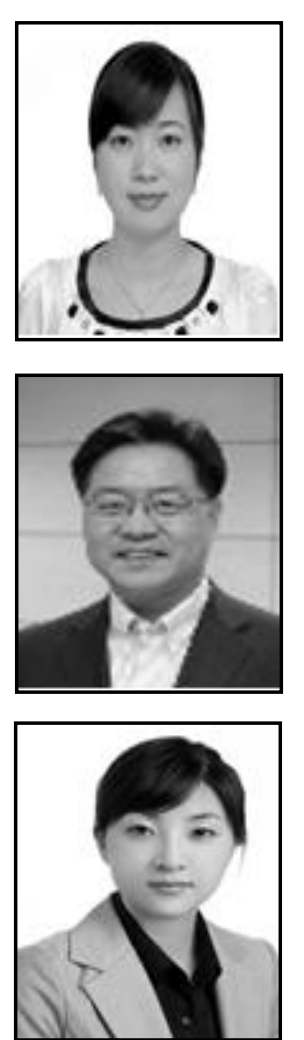

Won Jin Lee, she is a RN, APN, received B.A. (2011) at ChungAng University. She also received her M.S. (2016) in Advanced Practice Nursing at Nursing Science College of Health Sciences Ewha Womans University. She is working as a Cardiovascular Surgery Center in Kangbuk Samsung Hospital. She focuses her studies on Cardiovascular Patient Management and Care.

Sang Gwon Kang, he is a CFO, Ph.D, received his B.A. (1992) at Seoul Kidock University. He also received his M.S. (2000) in Hospital Management at YonSei University, and his Ph.D. in Business (2006) from Hansung University. Now, he is working for KangBuk Samsung Hospital as a CFO. He focuses his studies on health policy and health management.

Yun Yi Bang, she is a RN, APN, received B.A. (2008) at Korea National Open University of Nursing. She also received her M.S. (2016) in Advanced Practice Nursing at Nursing Science College of Health Sciences Ewha Womans University. She is working as a Cardiovascular Surgery Center in Kangbuk Samsung Hospital. She focuses her studies on Cardiovascular Patient Management and Care. 